\title{
Population-Based Study of Risk Factors for Coronary Heart Disease Among HIV-Infected Persons
}

\author{
John Y. Oh ${ }^{1,2}$, Kari Greene ${ }^{2}$, Haiou $\mathrm{He}^{2}$, Sean Schafer ${ }^{*}, 2$ and Katrina Hedberg ${ }^{2}$ \\ ${ }^{I}$ Epidemic Intelligence Service, Centers for Disease Control and Prevention, and ${ }^{2}$ Oregon Public Health Division, \\ Portland, Oregon, USA
}

\begin{abstract}
Preventing coronary heart disease (CHD) is critical to further extending survival among human immunodeficiency virus (HIV)-infected persons. Previously published findings of CHD risk factors in HIV-infected persons have been derived from facility-based cohort studies, which have limited representativeness for the HIV-infected population. State-specific, population-based surveillance data can assist health care providers and public health agencies in planning and evaluating programs that reduce CHD among HIV-infected persons. We describe CHD risk factors from the 2007-2008 Oregon Medical Monitoring Project, a population-based survey of HIV-infected persons receiving care that included both patient interview and medical record review. Among the $539 \mathrm{HIV}$-infected patients interviewed, the mean age was 45.5 years. Diagnoses from the medical record associated with CHD risk included preexisting CHD (5\%), diabetes (11\%), and hypertension (28\%). Current smoking was reported by $46 \%$; college graduates were less likely to smoke compared with those with lesser education $(21 \%$ versus $53 \%$, respectively; $P<.0001)$. Obesity was present among $17 \%$. Among the $65 \%$ of the survey group with lipid values available, $55 \%$ had high-density lipoprotein cholesterol (HDL) $<40 \mathrm{mg} / \mathrm{dL}$ and $42 \%$ had triglycerides $\geq 200 \mathrm{mg} / \mathrm{dL}$. Among the $15 \%$ of the survey group with either preexisting CHD or diabetes, $42 \%$ had a non-HDL $<130 \mathrm{mg} / \mathrm{dL}$ (target goal) and $38 \%$ smoked. Risk factors for CHD among HIVinfected persons, particularly smoking and dyslipidemia, should be managed aggressively. Ongoing surveillance is warranted to monitor changes in CHD risk factors in the HIV-infected population.
\end{abstract}

Keywords: Human immunodeficiency virus, coronary disease, risk factors, smoking, dyslipidemias.

\section{INTRODUCTION}

Because human immunodeficiency virus (HIV)-infected persons survive longer as a result of combination highly active antiretroviral therapy (HAART), preventing agerelated chronic diseases, including coronary heart disease (CHD), is critical to further extending survival. Mortality from non-AIDS-defining conditions currently accounts for one-half of total mortality in HIV-infected persons; the leading causes of mortality from non-AIDS-defining conditions include non-AIDS malignancy, non-AIDS infection, cardiovascular disease, which includes stroke and heart failure in addition to CHD, violence, and liver-related mortality [1]. Triant et al. reported that HIV-infected patients had 1.75 times the risk for acute myocardial infarction compared with non-HIV-infected patients, after adjusting for age, sex, race/ethnicity, hypertension, diabetes, and dyslipidemia, but not smoking [2]. HIV-infected persons are at high risk for CHD through multiple pathways. Previous studies have noted high prevalence of smoking $(50 \%-70 \%)$ among HIV-infected persons [3]. In addition, HIV infection and antiretroviral therapy (ART) can cause or exacerbate dyslipidemia [4]. Finally, HIV infection itself, especially with low $\mathrm{CD}^{+}$counts, increases the risk for $\mathrm{CHD}$ independent of any effect on lipids [5].

\footnotetext{
*Address correspondence to this author at the HIV/STD/TB Program, Oregon Public Health Division, 800 NE Oregon St., Ste. 1105, Portland OR 97232, USA; Tel: 971-673-0153; Fax: 971-673-0179;

E-mail: sean.schafer@state.or.us
}

Previously published findings of CHD risk factors in HIV-infected persons have been derived from facility-based cohort studies [6]. Yet HIV cohort studies, drawn primarily from urban-based HIV centers, have limited representativeness. For example, the racial and ethnic distributions of HIV-infected persons in cohort studies are not necessarily reflective of the HIV-infected population [7]. Population-based surveillance data can augment previously published findings of CHD risk factors from HIV cohort studies, and can assist health care providers and public health agencies in planning and evaluating programs that reduce CHD among HIV-infected persons. We describe CHD risk factors from a population-based survey of HIV-infected persons receiving care in Oregon.

\section{MATERIALS AND METHODS}

We used 2007-2008 Oregon data from the Medical Monitoring Project (MMP), a cross-sectional, populationbased, surveillance system that assessed behaviors, clinical outcomes, and the quality of care for HIV-infected persons who received health care for their HIV infection [7]. MMP used a 3-stage probabilistic sampling design, comprising state, provider, and patient levels. HIV providers were identified through laboratory tests consistent with HIV care, including viral load and $\mathrm{CD} 4{ }^{+}$counts. In Oregon, the MMP sample was augmented by inviting all patients cared for in rural facilities to participate. Participating patients were interviewed and their medical records were abstracted for a 12 -month period preceding the interview date. For the 2007 2008 data collection cycles, 539 patients in Oregon 
participated; the overall unweighted participation rate was $52.8 \%$.

We evaluated the presence of the following CHD risk factors: diagnosis of preexisting CHD, diabetes or hypertension; total cholesterol (TC) $\geq 240 \mathrm{mg} / \mathrm{dL}$; highdensity lipoprotein cholesterol (HDL) $<40 \mathrm{mg} / \mathrm{dL}$; triglycerides $\geq 200 \mathrm{mg} / \mathrm{dL}$; current smoking; and obesity, defined as body mass index $>30 \mathrm{~kg} / \mathrm{m}^{2}$. Smoking was determined from patient interview; all other risk factors were abstracted from the medical record. For patients with preexisting $\mathrm{CHD}$ or diabetes, we determined the proportion who met a non-HDL target goal of $<130 \mathrm{mg} / \mathrm{dL}$, in accordance with National Cholesterol Education Program (NCEP) Adult Treatment Panel (ATP) III guidelines [8]. The non-HDL, calculated by subtracting HDL from total cholesterol, was used because, in the presence of hypertriglyceridemia, non-HDL better correlates with CHD risk than does low-density lipoprotein cholesterol (LDL). (A non-HDL of $<130 \mathrm{mg} / \mathrm{dL}$ is comparable to an LDL of $<100$ $\mathrm{mg} / \mathrm{dL}$; a non-HDL of $>160 \mathrm{mg} / \mathrm{dL}$ is comparable to LDL $>130 \mathrm{mg} / \mathrm{dL}$.) We compared participants in an age group at higher risk for $\mathrm{CHD}$ (males $\geq 45$ years and females $\geq 55$ years), as defined by NCEP ATP III guidelines, with younger participants.

All analyses were weighted to account for the complex survey method and rural oversample. We compared differences between younger and older age groups with chisquare tests; a $P$ value $<.05$ was considered statistically significant.

\section{RESULTS}

Among the 539 HIV-infected patients interviewed in 2007-2008, the mean age of the survey group was 45.5 years (range: 18-76 years). Interviews occurred a mean of 12.4 years after HIV diagnosis and, for $95 \%$ of the survey group currently taking ARTs, a mean of 10.2 years after initiation of ART.

For the entire survey group, $5 \%$ had a diagnosis of CHD; $11 \%$ had diabetes; and $28 \%$ had hypertension (Table 1). Among the entire group, $6 \%$ had 2 diagnoses among CHD, diabetes, and hypertension, and $1 \%$ had all three of these conditions associated with increased cardiovascular risk. Current smoking was reported by $46 \%$; college graduates were less likely to smoke compared with those with lesser education $(21 \%$ versus $53 \%$, respectively; $P<.0001$ ). Obesity was present among $17 \%$. TC, HDL, or triglycerides were available for $65 \%$ of the survey group. The mean values for TC and HDL were $183.9 \mathrm{mg} / \mathrm{dL}$ and $39.7 \mathrm{mg} / \mathrm{dL}$, respectively. The triglycerides distribution was skewed to the right; median triglyceride level was $178 \mathrm{mg} / \mathrm{dL}$. Nine percent had TC $\geq 240 \mathrm{mg} / \mathrm{dL} ; 55 \%$ had HDL $<40 \mathrm{mg} / \mathrm{dL}$; and $42 \%$ had triglycerides $\geq 200 \mathrm{mg} / \mathrm{dL}$.

Table 1. Prevalence of Demographic and HIV Infection Characteristics, and CHD Risk Factors Among HIV-Infected Persons, by Age Risk Group — Oregon, 2007-2008

\begin{tabular}{|c|c|c|c|c|c|}
\hline & $\begin{array}{c}\text { Number of } \\
\text { Patients } \\
\text { with Data } \\
\text { Available }\end{array}$ & $\begin{array}{l}\% \text { of Patients } \\
\text { with Data } \\
\text { Available Having } \\
\text { Characteristic* } \\
\text { (95\% CI) }\end{array}$ & $\begin{array}{c}\text { Younger Age } \\
\text { Risk Group } \\
\text { Males }<45 \text { Yrs, } \\
\text { Females }<55 \text { Yrs \% } \\
(\mathbf{9 5 \%} \text { CI })(n=263)\end{array}$ & $\begin{array}{c}\text { Older Age } \\
\text { Risk Group } \\
\text { Males } \geq 45 \text { Yrs, } \\
\text { Females } \geq 55 \text { Yrs \% } \\
(95 \% \text { CI })(n=276)\end{array}$ & $\begin{array}{l}\text { Prevalence Ratio } \\
\text { (Older Age Risk } \\
\text { Group/Younger } \\
\text { Age Risk Group) }\end{array}$ \\
\hline \multicolumn{6}{|l|}{ Demographic Characteristics } \\
\hline Male & 537 & $90(87-92)$ & $82(77-87)$ & $98(96-99)$ & $1.2(1.1-1.3)$ \\
\hline Non-Hispanic white race & 536 & $75(70-80)$ & $67(57-75)$ & $84(79-88)$ & $1.2(1.1-1.4)$ \\
\hline College graduates & 538 & $19(16-23)$ & $14(9-18)$ & $25(19-31)$ & $1.9(1.2-2.8)$ \\
\hline \multicolumn{6}{|l|}{ HIV Infection Characteristics } \\
\hline Currently on antiretroviral therapy & 508 & $95(92-97)$ & $91(86-95)$ & $98(97-100)$ & $1.1(1.0-1.1)$ \\
\hline Prior diagnosis of $\mathrm{CHD}$ & 539 & $5(3-8)$ & $1(0-2)$ & $10(6-14)$ & $8.7(2.6-29.1)$ \\
\hline Prior diagnosis of diabetes & 539 & $11(7-16)$ & $9(1-17)$ & $14(9-18)$ & $1.5(0.6-3.8)$ \\
\hline Prior diagnosis of hypertension & 539 & $28(23-32)$ & $16(11-20)$ & $40(34-47)$ & $2.6(1.8-3.6)$ \\
\hline Current smoking & 538 & $46(41-51)$ & $54(47-62)$ & $38(32-45)$ & $0.7(0.6-0.9)$ \\
\hline Current obesity (BMI $\geq 30$ ) & 449 & $17(13-21)$ & $23(17-29)$ & $11(6-15)$ & $0.5(0.3-0.7)$ \\
\hline $\mathrm{TC} \geq 240 \mathrm{mg} / \mathrm{dL}$ & 343 & $9(6-13)$ & $7(2-11)$ & $12(7-17)$ & $1.8(0.8-3.8)$ \\
\hline $\mathrm{HDL}<40 \mathrm{mg} / \mathrm{dL}$ & 345 & $55(48-61)$ & $60(50-70)$ & $51(43-58)$ & $0.8(0.7-1.1)$ \\
\hline Triglycerides $\geq 200 \mathrm{mg} / \mathrm{dL}$ & 301 & $42(35-49)$ & $44(31-57)$ & $41(33-49)$ & $0.9(0.7-1.3)$ \\
\hline
\end{tabular}

Note. CI, confidence interval; CHD, coronary heart disease; HDL, high-density lipoprotein; TC, total cholesterol; BMI, body mass index.

* All data are weighted to state population data. 
In bivariate analysis, compared with those in the younger age group, patients in the older age group were more likely to be male, be non-Hispanic white, have graduated from college, be currently taking antiretroviral therapy, and have undetectable viral load. For CHD risk factors, compared with those in the younger age group, patients in the older age group (males $\geq 45$ years and females $\geq 55$ years) had higher prevalence of CHD and hypertension diagnoses, but lower prevalence of smoking and obesity (Table 1).

Among the $15 \%$ of the survey group with either preexisting CHD or diabetes, $42 \%$ had a non-HDL $<130$ $\mathrm{mg} / \mathrm{dL} ; 21 \%$ had a non-HDL $>160 \mathrm{mg} / \mathrm{dL}$. Current smoking was reported among $38 \%$ of those with preexisting CHD or diabetes.

\section{DISCUSSION}

In this cross-sectional, population-based survey, we determined that Oregon HIV-infected persons had CHD risk factors notable for high rates of smoking and dyslipidemia, findings comparable to reports from HIV cohort studies $[5,6]$. In the DAD study, a multinational collaboration of previously established cohorts, the prevalences of current smoking at baseline was $51.5 \%$ and total cholesterol $\geq 240$ $\mathrm{mg} / \mathrm{dL}$ was $22.2 \%$, compared with $46 \%$ and $9 \%$, respectively, in our study [6]. In DAD, the prevalences of previous cardiovascular disease $(1.4 \%)$, hypertension $(8.5 \%)$, and diabetes $(2.5 \%)$ at baseline were lower than our study, likely because the median age in DAD at baseline was 39 years age, compared with the mean age of 45.5 years age in this study. In contrast, in the HIV Outpatient Study, a cohort study of HIV-infected patients receiving care at 10 U.S. HIV specialty clinics, with median age of 42 years at baseline, $49 \%$ had hypertension and $9 \%$ had diabetes at baseline; 55\% were current or former smokers [5]. As some CHD risk factors are highly influenced by patient age, ongoing public health surveillance of risk factors in HIVinfected persons, through population-based surveys, can best monitor dynamic patterns of health.

Current smoking was $>2.5$ times as prevalent among HIV-infected persons in Oregon (46\%) compared with adults statewide (18\%) [9]. Especially concerning was the high smoking prevalence among patients with preexisting CHD or diabetes, who are at highest risk for myocardial infarction and CHD death. Similar to other reports, we confirmed that smoking prevalence was inversely associated with education [10]. Although patients in the older age group were better educated, age differences in smoking prevalence persisted when stratified by education level (data not shown). Survivor bias, however, might have partly explained the lower smoking prevalence among older HIV-infected persons. We did not have information regarding the extent of smoking cessation counseling or treatment to assess to what extent smoking was adequately addressed in clinical settings. Our findings reinforce that intensive strategies to combat smoking and overcome barriers to quitting are needed for HIV-infected persons.

Participants in the Oregon MMP had lipid patterns characterized by low HDL and high triglycerides. We found $55 \%$ of Oregon HIV-infected persons had a HDL $<40 \mathrm{mg} / \mathrm{dL}$ and $42 \%$ had triglycerides $\geq 200 \mathrm{mg} / \mathrm{dL}$, population estimates that were likely overstated because patients with dyslipidemia were more likely to have had lipid panels drawn over a 12 month period in this cross-sectional survey. Other studies in HIV-infected persons have similarly detected high prevalence of dyslipidemia, albeit with lower estimates of low HDL. In the HIV-HEART study, Reinsch et al. found $27.5 \%$ had low HDL and $39 \%$ had elevated triglycerides [11]; in the Swiss HIV cohort study, Glass et al. found $37.2 \%$ had low HDL and 35.7\% had elevated triglycerides [12]. HDL decreases early in HIV infection and typically does not completely return to premorbid levels with viral suppression. Especially concerning was the prevalence of dyslipidemia among HIV-infected persons with preexisting CHD or diabetes. Fewer than one-half of patients with CHD or diabetes had a non-HDL $<130 \mathrm{mg} / \mathrm{dL}$, the target goal; one-fifth had a non-HDL $>160 \mathrm{mg} / \mathrm{dL}$. Although we did not have information about dietary interventions or drug therapy to manage dyslipidemia, our findings reveal that lipid management among the highest-risk group for CHD was suboptimal.

Assisting HIV-infected persons in maintaining a healthy weight is especially relevant for younger persons, who had higher prevalence of obesity $(23 \%)$. Overall, however, obesity was one-half as prevalent among Oregon HIVinfected persons (17\%) compared with NHANES (34\%) [13]. Weight loss from advanced HIV infection did not account for lower obesity; no association existed between obesity and viral load or $\mathrm{CD}^{+}$count (data not shown). Finally, we identified prevalences of preexisting heart disease, diabetes, and hypertension that, while divergent from some HIV cohort studies, were comparable to the U.S. adult population with similar age and sex distribution.

This study had certain limitations. First, the sampling frame for the study only included HIV-infected persons who had established care. Thus, the prevalences for diagnoses of CHD, diabetes, and hypertension might have been higher because persons with symptomatic disease might have been more likely to seek care and because persons in care were more likely to have been diagnosed for subclinical conditions. Second, as described previously, a high proportion of the survey group had missing lipid and BMI data. Lipid results were abstracted only during the 12-month surveillance period. If patients without lipid tests recorded were more likely to be judged at low risk for CHD by the clinician or more likely to have had desirable lipid results before the surveillance period, our estimates for the prevalence of dyslipidemia would have been high. Even if all the patients in this survey who had missing lipid data were assumed to have normal lipids, however, $1 / 4$ to $1 / 3$ of Oregon HIV-infected persons would have had dyslipidemia, a higher prevalence than the national adult population in the National Health and Nutrition Examination Survey [14]. Third, because we did not have blood pressure measurements, we were unable to individually calculate the Framingham risk score, which would have provided a more detailed assessment of CHD risk among this population. Risk prediction models, however, should be validated among HIV-infected persons because the Framingham risk score is considered to underestimate CHD risk among the HIVinfected population [15]. Finally, our survey was limited to Oregon HIV-infected persons, and findings might not necessarily apply to the national population. 


\section{CONCLUSIONS}

Our findings reinforce the need to aggressively assess and manage risk factors for CHD, particularly smoking and lipids, among the HIV-infected population. With increasing survival and years living with HIV infection, many will transition into age groups with greater prevalences of CHD and other medical conditions, such as hypertension and diabetes, which impose risk of CHD. Further prolonging survival among HIV-infected persons will increasingly be influenced by non-AIDS-defining conditions. Ongoing public health surveillance of health risk behaviors specific to HIV-infected persons is essential to further improving the health of this population. Our novel use of population-based surveillance data from MMP to evaluate CHD risk factors among HIV-infected persons might be adopted by other states and expanded nationally.

\section{NOTE}

The findings and conclusions in this report are those of the author(s) and do not necessarily represent the official position of the Centers for Disease Control and Prevention.

\section{ACKNOWLEDGEMENTS}

We thank Shelly Grigsby, Sheryl Lyss, Julie Maher, Denise Skrypkar, and Tyler Smith for their support of this investigation. This project was funded by Centers for Disease Control and Prevention (CDC) Grant Number U62/CCU024422-04.

\section{CONFLICT OF INTEREST}

The authors confirm that this article content has no conflict of interest.

\section{REFERENCES}

[1] The Antiretroviral Therapy Cohort Collaboration. Causes of death in HIV-1-infected patients treated with antiretroviral therapy, 19962006: collaborative analysis of $13 \mathrm{HIV}$ cohort studies. Clin Infect Dis 2010; 50: 1387-96.

[2] Triant VA, Lee H, Hadigan C, Grinspoon SK. Increased acute myocardial infarction rates and cardiovascular risk factors among patients with human immunodeficiency virus disease. J Clin Endocrinol Metab 2007; 92: 2506-12.

[3] Nahvi S, Cooperman NA. Review: the need for smoking cessation among HIV-positive smokers. AIDS Educ Prev 2009; 21(3 Suppl): 14-27.

[4] Kotler DP. HIV and antiretroviral therapy: lipid abnormalities and associated cardiovascular risk in HIV-infected patients. J Acquir Immune Defic Syndr 2008; 49: S79-S85.

[5] Lichtenstein KA, Armon C, Buchacz K, et al. Low CD4 $4^{+} \mathrm{T}$ cell count is a risk factor for cardiovascular disease events in the HIV Outpatient Study. Clin Infect Dis 2010; 51: 435-47.

[6] Friis-Moller N, Weber R, Reiss P, et al. Cardiovascular disease risk factors in HIV patients - association with antiretroviral therapy. Results from the DAD study. AIDS 2003; 17: 1179-93.

[7] McNaghten $\mathrm{AD}$, Wolfe MI, Onorato I, et al. Improving the representativeness of behavioral and clinical surveillance for persons with HIV in the United States: the rationale for developing a population-based approach. PloS One 2007; 2: e550. Available at: http: //www.plosone.org [Accessed February 1, 2011].

[8] Expert panel on detection evaluation and treatment of high blood cholesterol in adults. Third report of the national cholestero education program (NCEP) expert panel on detection, evaluation, and treatment of high blood cholesterol in adults (adult treatment panel III) final report. Circulation 2002; 106: 3143-421.

[9] Centers for disease control and prevention. State-specific prevalence of cigarette smoking among adults aged $\geq 18$ yearsUnited States, 2009. MMWR 2010; 59: 1400-6.

[10] Centers for disease control and prevention. Vital signs: current cigarette smoking adult adults aged $\geq 18$ years-United States, 2009 . MMWR 2010; 59: 1135-40.

[11] Reinsch N, Neuhaus K, Esser S, et al. Are HIV patients undertreated? Cardiovascular risk factors in HIV: results of the HIV-HEART study. Eur J Cardiol Prev 2012; 19(2): 267-74.

[12] Glass TR, Ungsedhapand C, Wolbers M, et al. Prevalence of risk factors for cardiovascular disease in HIV-infected patients over time: the Swiss HIV cohort study. HIV Med 2006; 7: 404-10.

[13] National Center for Health Statistics. Health, United States, 2009: With special feature on medical technology. Hyattsville, MD: US Department of Health and Human Services, Centers for Disease Control and Prevention 2010.

[14] Cohen JD, Cziraky MJ, Cai Q, et al. 30-year trends in serum lipids among United States adults: results from the National Health and Nutrition Examination Surveys II, III, and 1999-2006. Am J Cardiol 2010; 106: 969-75.

[15] Schambelan M, Wilson PWF, Yarasheski KE, et al. Development of appropriate coronary heart disease risk prediction models in HIV-infected patients. Circulation 2008; 118: e48-e53. 